
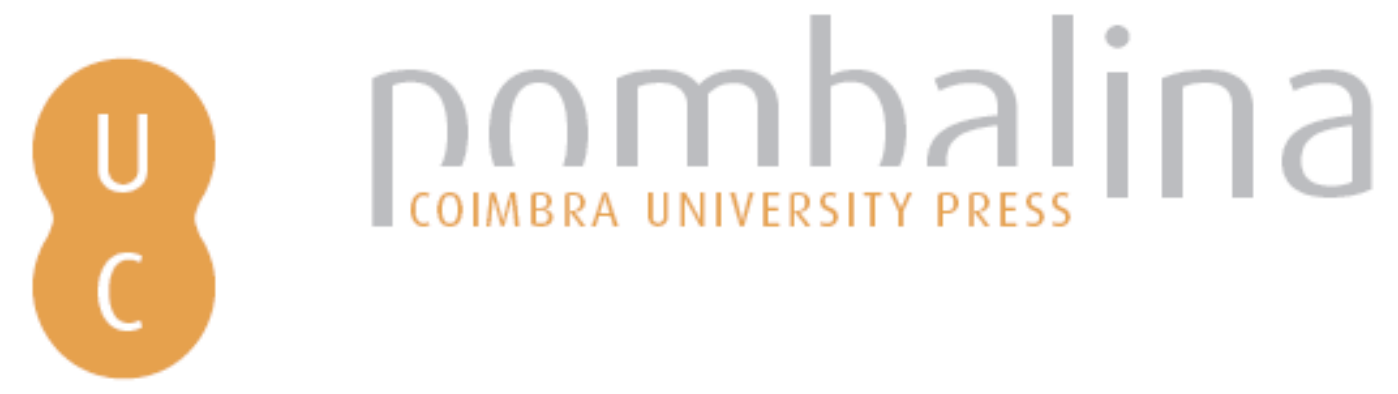

\title{
Caracterização morfoestrutural do Bordo Ocidental do Planalto da Humpata (SW Angola) com recurso a técnicas de deteção remota
}

\author{
Autor(es): $\quad$ Lopes, F. C.; Mantas, V.; Pereira, A.; Mpengo, H. \\ Publicado por: Imprensa da Universidade de Coimbra \\ URL \\ persistente: URI:http://hdl.handle.net/10316.2/31385 \\ DOI: $\quad$ DOI:http://dx.doi.org/10.14195/978-989-26-0534-0_5 \\ Accessed : $\quad$ 26-Apr-2023 11:15:29
}

A navegação consulta e descarregamento dos títulos inseridos nas Bibliotecas Digitais UC Digitalis, UC Pombalina e UC Impactum, pressupõem a aceitação plena e sem reservas dos Termos e Condições de Uso destas Bibliotecas Digitais, disponíveis em https://digitalis.uc.pt/pt-pt/termos.

Conforme exposto nos referidos Termos e Condições de Uso, o descarregamento de títulos de acesso restrito requer uma licença válida de autorização devendo o utilizador aceder ao(s) documento(s) a partir de um endereço de IP da instituição detentora da supramencionada licença.

Ao utilizador é apenas permitido o descarregamento para uso pessoal, pelo que o emprego do(s) título(s) descarregado(s) para outro fim, designadamente comercial, carece de autorização do respetivo autor ou editor da obra.

Na medida em que todas as obras da UC Digitalis se encontram protegidas pelo Código do Direito de Autor e Direitos Conexos e demais legislação aplicável, toda a cópia, parcial ou total, deste documento, nos casos em que é legalmente admitida, deverá conter ou fazer-se acompanhar por este aviso.

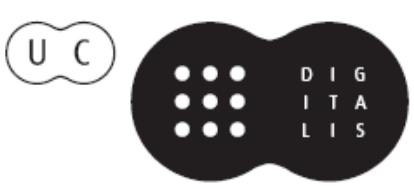





\title{
CARACTERIZAÇÃO MORFOESTRUTURAL DO BORDO OCIDENTAL DO PLANALTO DA HUMPATA (SW DE ANGOLA) COM RECURSO A TÉCNICAS DE DETEÇÃO REMOTA
}

\author{
MORPHO-STRUCTURAL CHARACTERIZATION OF THE \\ WESTERN EDGE OF THE HUMPATA PLATEAU (SW ANGOLA) \\ BASED ON REMOTING SENSE TECHNIQUES
}

F. C. Lopes ${ }^{1,2}$, V. Mantas ${ }^{3}$, A. Pereira ${ }^{2,3} \&$ H. Mpengo ${ }^{4}$

Resumo - Efetuou-se o reconhecimento das principais características morfoestruturais do bordo ocidental do planalto da Humpata (SW de Angola), utilizando técnicas de Deteção Remota aplicadas a imagens de satélite. Foram identificados e caracterizados aspetos morfológicos e sistemas de lineamentos estruturais regionais cuja presença no terreno foi confirmada por reconhecimento de campo em vários locais do planalto. O resultado deste estudo tem importantes implicaçôes, quer do ponto de vista da cartografia geológica e das interpretaçóes tectónicas regionais, quer no âmbito das políticas de ordenamento do território, em áreas como a hidrogeologia ou a estabilidade de taludes.

Palavras-chave - Angola; Planalto da Humpata; Deteção remota; Caracterização morfoestrutural

Abstract - The goal of this work is to recognize the main morphostructural features of the western edge of the Humpata plateau (SW Angola) using Remote Sensing techniques applyed to satellite images. Morphological aspects and the main regional lineaments systems were identified and characterized and, in some cases, confirmed by field work. This study has important

${ }^{1}$ Centro de Geofísica, Faculdade de Ciências e Tecnologia da Universidade de Coimbra, Av. Dr. Dias da Silva, 3000-134 Coimbra, Portugal; fcarlos@dct.uc.pt

2 Departamento de Ciências da Terra, Faculdade de Ciências e Tecnologia da Universidade de Coimbra, 3000-272 Coimbra, Portugal; apereira@dct.uc.pt

3 IMAR, Faculdade de Ciências e Tecnologia da Universidade de Coimbra, 3000-272 Coimbra, Portugal; vasco.mantas@gmail.com

4 UPRA-Lubango, Angola; mpengoh@yahoo.com.br 
implications from the point of view of geological mapping and regional tectonics as well as in land use planning or other areas such as hydrogeology or geotechnics.

Keywords - Angola; Humpata plateau; Remote sensing; morphostructural characterization

\section{1 - Introduçáo}

O planalto da Humpata, situado no sudoeste angolano, entre os paralelos 14030' S e $15^{\circ} 30^{\prime} \mathrm{S}$ e os meridianos $13^{\circ} 15^{\prime}$ E e 13 45' E, constitui o setor mais central e elevado (2230 m) do grande planalto da Huila, que se estende de Tchongorói, Província de Benguela, a norte, até Oncôncua, Província do Cunene, a sul (Fig. 1; MPENGO et al., 2011).

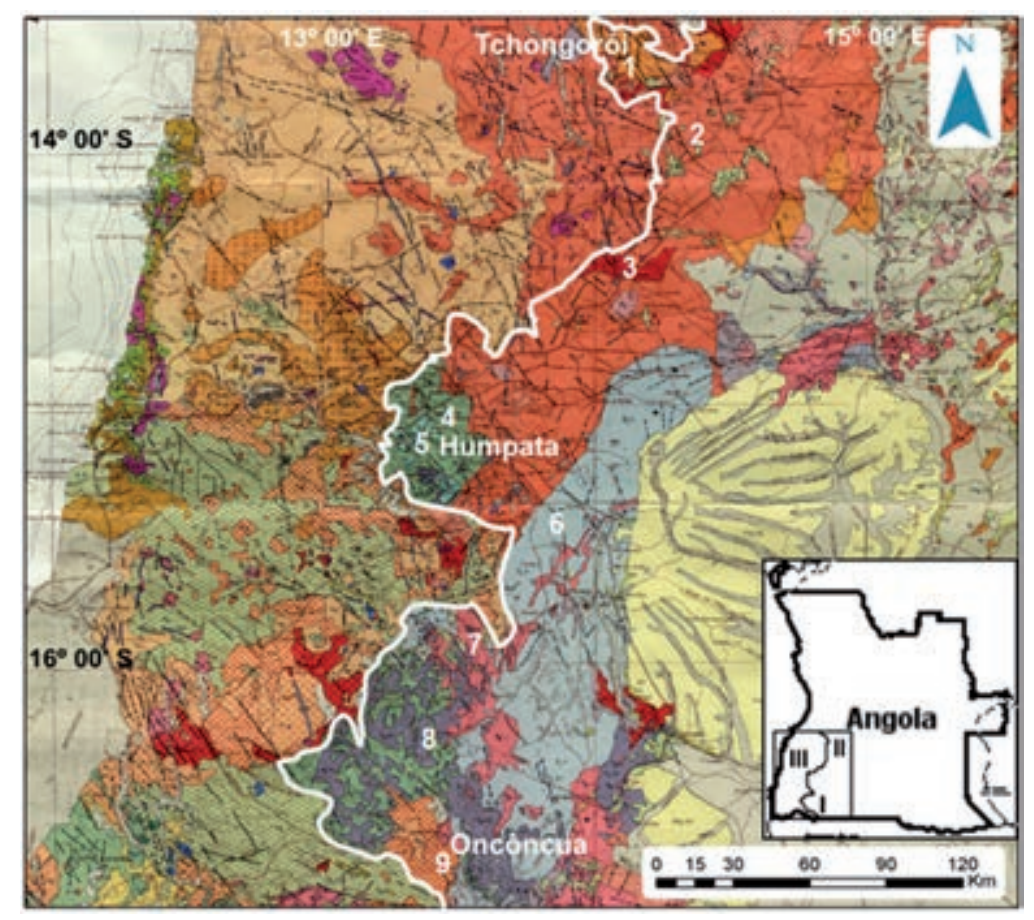

Fig. 1 - Extrato da folha 3 da carta geológica de Angola à escala 1:1000000 (MATIAS, 1980), com a localizaçấo geográfica do bordo ocidental do planalto da Huíla (contorno a branco) e as diferentes litologias que o constituem ao longo dos seus vários setores. 1. Granitos porfiroblásticos eburneanos; 2. Granitos biotíticos, granodioritos e dioritos eburneanos; 3. Granitos e gneisses eburneanos; 4. Quartzitos da Chela, pan-africanos; 5. Calcários da Leba-Tchamalindi, pan-africanos; 6. Complexo Gabro-anortosítico, limpopo-liberiano; 7. Granitos Vermelhos do Sudoeste, kibarianos; 8. Noritos e doleritos, pan-africanos; 9. Dioritos e granodioritos do Sudoeste, limpopo-liberianos. Unidades geomorfológicas: I. Planalto Antigo; II. Cadeia Marginal de Montanhas; III. Zona de Transição (adaptado de MPENGO et al., 2011). 
É nele que se situa, a uma altitude de cerca de $1900 \mathrm{~m}$, a cidade do Lubango. Segundo MARQUES (1977), faz parte da unidade geomorfológica II-Cadeia Marginal de Montanhas, representada por relevos de desnível muito acentuado. Para oeste, esta unidade passa abruptamente à unidade III, a Zona de Transiçáo, que se estende paralela ao Atlântico, representada por uma sucessão de patamares aplanados. Esta passagem traduz-se no terreno por um apreciável degrau de erosáo que, em algumas zonas, apresenta o aspeto de uma verdadeira escarpa, com mais de $1000 \mathrm{~m}$ de altura, muito recortada, por vezes revestida de rocha nua (Fig. 2A). A intensa fraturação, que se observa no seu bordo ocidental, facilita a ação erosiva e favorece os movimentos de massa e as acumulaçôes de sopé. É comum a formação de fendas e canhóes, alguns deles profundamente incisos na parede do maciço e de grande impacto visual, como é o caso da Fenda da Tundavala (Serra da Chela; Fig. 2B).

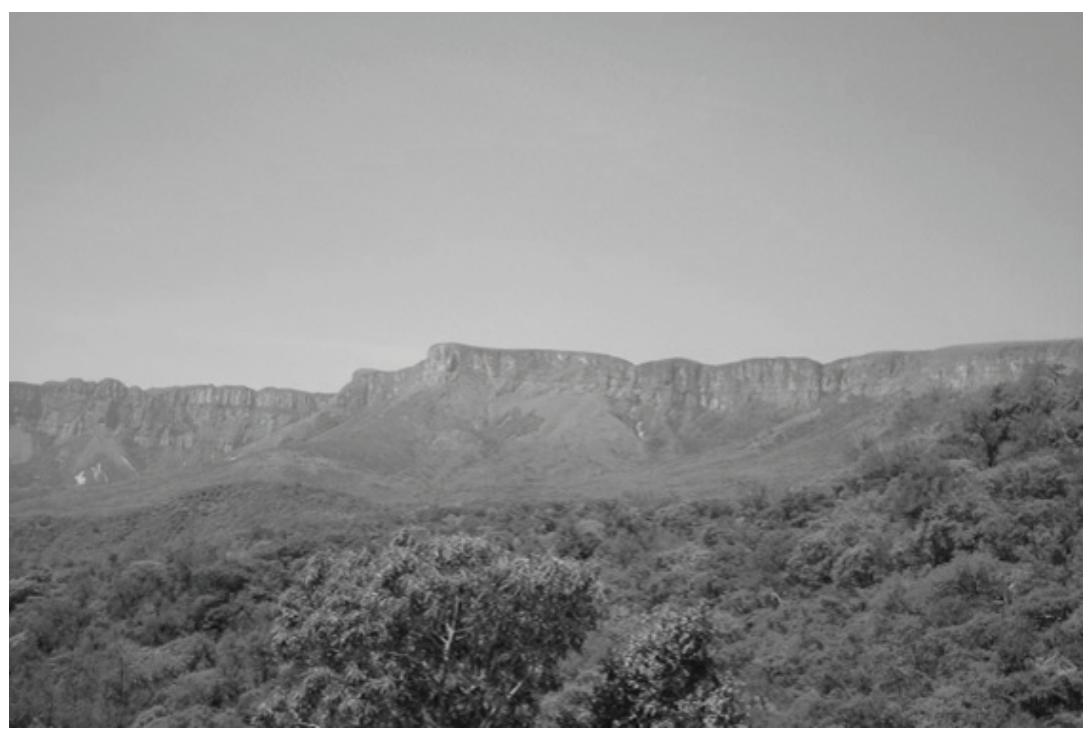

Fig. 2-A - A imponente escarpa do bordo ocidental do Planalto da Humpata.

Do ponto de vista geológico, integra, conjuntamente com os outros setores do planalto da Huíla, o chamado Bloco Angolano do Cratáo Proterozóico do Congo (e.g., DELOR et al., 2008), cujo interior se manteve estável após os ciclos orogénicos Limpopo-Liberiano (c. $2680 \mathrm{Ma}$ a c. $2820 \mathrm{Ma}$ ) e Eburneano e /ou Tadiliano (c. $2100 \mathrm{Ma}$ c. a c. $2000 \mathrm{Ma}$ ), mas cujas zonas periféricas foram reativadas e remobilizadas durante os ciclos orogénicos Maiombiano $(1300 \pm 200 \mathrm{Ma})$, Kibarino $(1300 \pm 100 \mathrm{Ma})$ e Pan-Africano (c. $975 \mathrm{Ma}$ a c. 550Ma) (e.g., CARVALHO, 1983, 1993; FERREIRA DA SILVA, 2009). O presente trabalho tem como objetivos o reconhecimento dos principais sistemas de lineamentos estruturais do bordo ocidental deste planalto e a definiçâo das suas principais características morfoestruturais, como complemento à cartografia estrutural, através da interpretação de dados digitais de deteçâo remota espacial. 


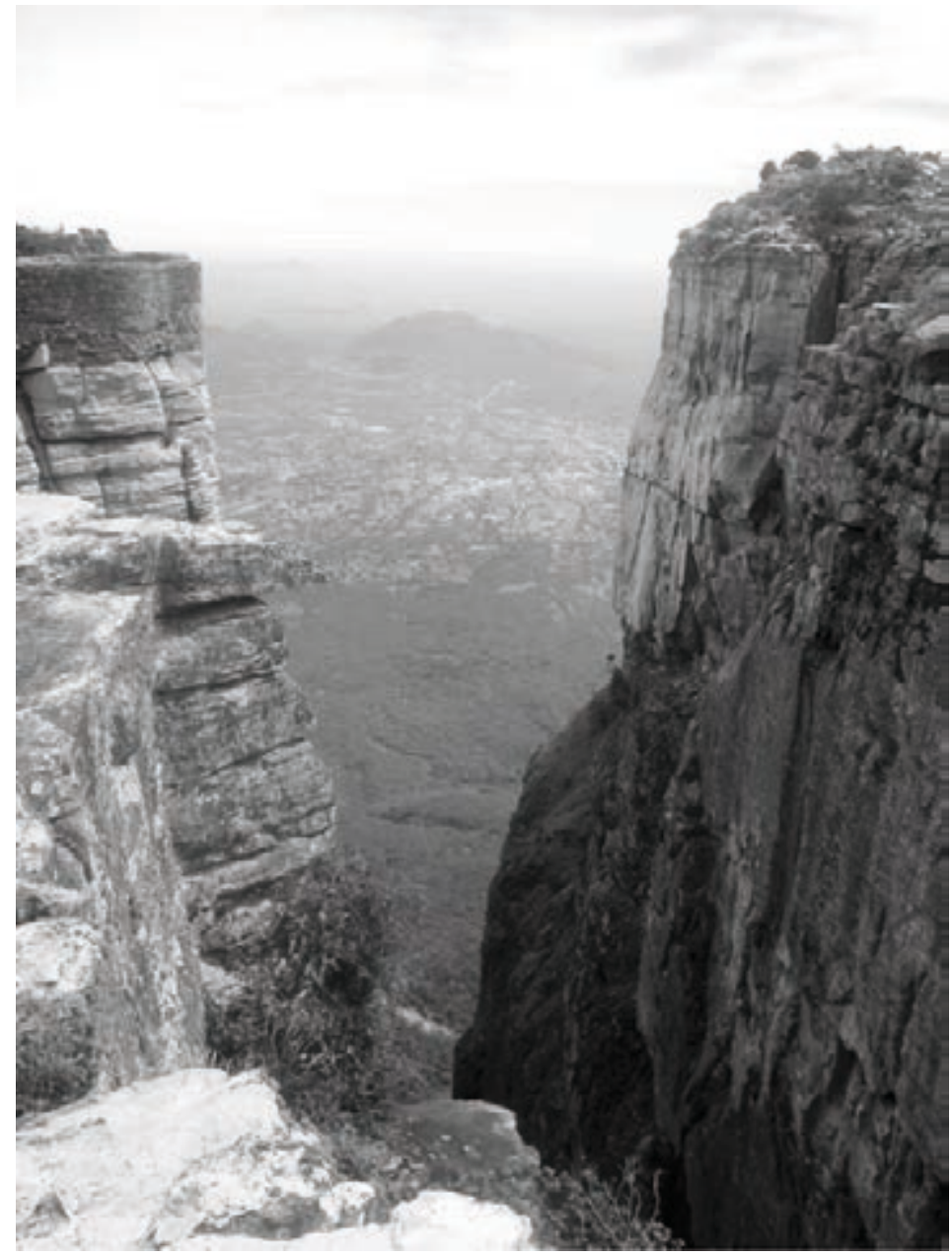

Fig. 2-B - A vertiginosa fenda da Tundavala.

\section{2 - Metodologia}

Para o presente estudo recorreu-se a um modelo digital de terreno (DEM) construído através de dados ASTER (GDEM, obtido através do LP DAAC da NASA). Sobre este foram aplicadas técnicas de análise de imagem centradas no realce dos alinhamentos estruturais. Estes procedimentos, executados no software ArcGIS 10, recorreram à execução de filtros direcionais sobre o DEM e análise textural. A interpretação das imagens resultantes foi feita de forma visual e digital, recorrendo, sempre que possível, ao apoio da cartografia geológica disponível à escala 1:1000000. Os dados topográficos foram ainda complementados, quando necessário, por informação do Landsat-7 ETM+, obtida junto da United States Geological Survey. Os dados Landsat foram submetidos a uma correção 
simples, através da conversão a refletância aparente, seguida de minimização dos efeitos atmosféricos pelo método do "Dark Pixel" (CHAVEZ, 1996). A fotointerpretação efetuada foi confirmada, sempre que possível, por reconhecimento de campo em vários locais do planalto da Humpata.

\section{3 - Geomorfologia e geologia}

O bordo do planalto da Humpata possui uma forma em semi-elipse, com a convexidade voltada para oeste e o eixo maior segundo NE-SW. Apresenta-se muito recortado em facetas orientadas, alternadamente, segundo NW-SE e NE-SW, formando pequenos polígonos, a oeste e a sudoeste, enquanto a nordeste assume um aspeto dendriforme. Esta característica traduz-se no terreno em fraturas, canhôes e fendas bastante incisivos, que se abrem para o vazio do vale a ocidente, de que se destaca a monumental Fenda da Tundavala (Fig. 2B), situada a noroeste da cidade do Lubango, perto da qual se alcançam as cotas mais elevadas deste bordo (2326 a 2330m). O relevo é mais elevado e aplanado na zona centro-oeste do que nas extremidades nordeste e sudoeste, onde se apresenta mais acidentado e relativamente mais baixo. Torna-se mais baixo e suave à medida que se caminha para leste e sudeste, em direção ao interior. A nordeste, o relevo parece, por vezes, condicionado por corredores de direção NE-SW e NW-SE, onde vales profundos e cristas em forma de sigmóides em " $S$ " e " $Z$ ", respetivamente, aparecem dispostos em "escadaria".

Do ponto de vista litológico (Fig. 1), o bordo do planalto é aqui é maioritariamente constituído pelos quartzitos do Grupo da Chela (unidade $\mathrm{P}_{\mathrm{A}} \mathrm{Ch}$; MATIAS, 1980), onde se intercalam os calcários dolomíticos da formação da Leba-Tchamalindi (unidade $\mathrm{P}_{\mathrm{A}} \mathrm{L}$; MATIAS, 1980), ambos de idade pan-africana. Para nordeste e no extremo sudeste passa à unidade $\mathrm{P}_{\mathrm{C}} \gamma$ (granitos biotíticos, granodioritos e dioritos) de idade eburneana. $\mathrm{O}$ ressalto para a peneplanície traduz-se, litologicamente, pela passagem aos granitos do Caraculo-Bibala (unidade P $\gamma$ C; MATIAS, 1980), a oeste e noroeste, e aos granodioritos e dioritos do Sudoeste (unidade PA; MATIAS, 1980), a sudoeste, de idade limpopo-liberiana (2200 a $2700 \mathrm{Ma}$ ). Nesta peneplanície destacam-se relevos de dureza preferencialmente direcionados segundo NW-SE, um dos quais exibe a forma de um largo sigmóide em "S", constituídos por rochas básicas e ultrabásicas do Complexo Gabro-Anortosítico (unidade $\mathrm{P}_{\mathrm{C}} \beta-\mathrm{P}_{\mathrm{C}} \phi ;$ MATIAS, 1980).

\section{4 - Caracterização morfo-estrutural}

Da análise morfoestrutural ao bordo ocidental do planalto da Humpata, com base no modelo digital de terreno, foi possível interpretar os seguintes sistemas de lineamentos dominantes (Figs. 3 e 4):

- Sistema NW-SE (N45W-N60'W) - é o sistema de lineamentos mais penetrativo e predominante, recortando o bordo do planalto em facetas com a mesma orientação, materializadas em canhóes e fendas, de que se destaca a Fenda da Tundavala (Fig. 2B). Estes 
lineamentos constituem verdadeiros corredores, que se prolongam para noroeste, através da peneplaníce, e que se traduzem, quer em falhas profundas de soco, ou zonas de falha, ao longo das quais se implantaram, por vezes, rochas doleríticas, quer em fraturas e diaclases. Reconhecem-se, tanto nos taludes da Estrada da Leba e da estrada de acesso à Tundavala, onde as rochas aparecem profundamente cataclasadas e milonitizadas (Fig. 5), como em alguns afloramentos do planalto da Humpata, como sistema de diáclase (Fig. 6). As falhas deste sistema terão atuado como normais durante a fase de rifte do Cretácico inferior.

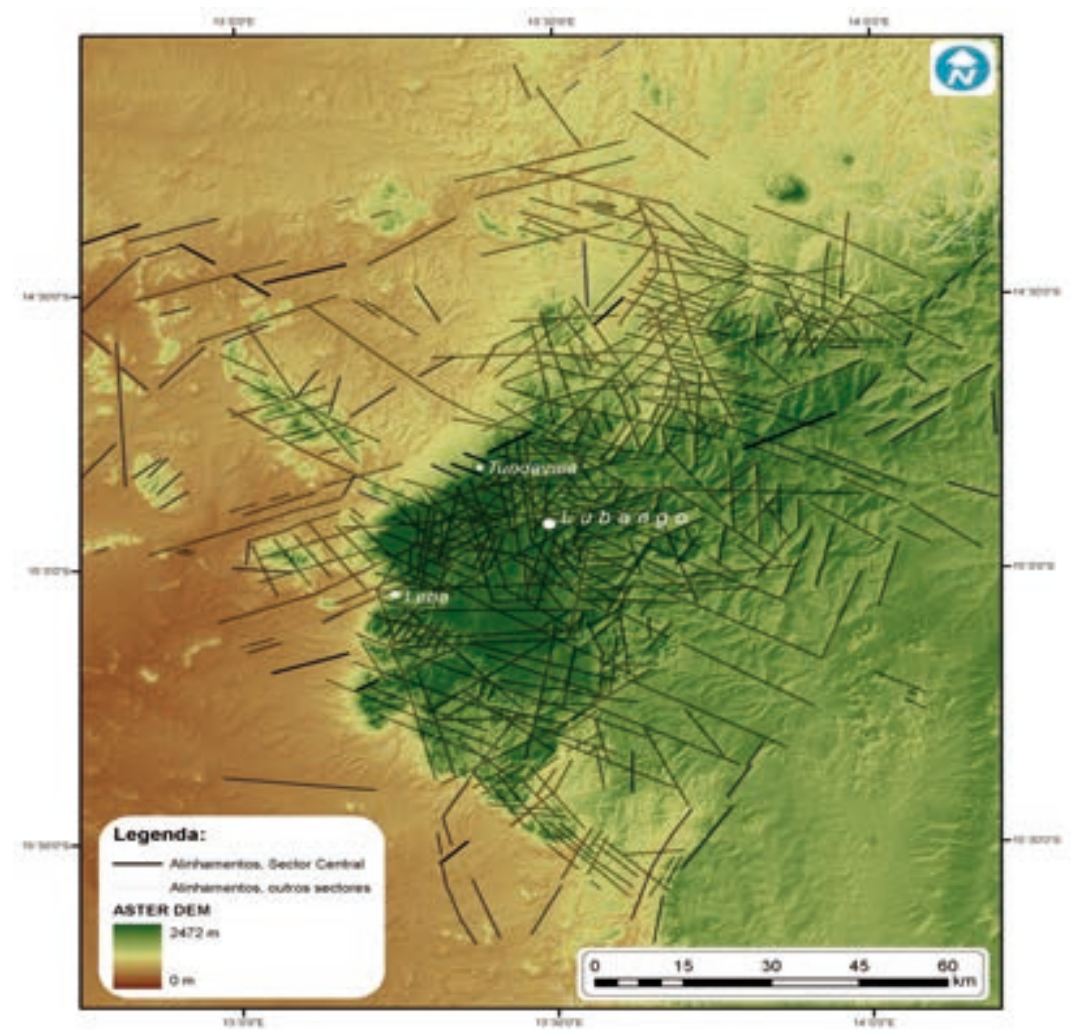

Fig. 3 - Modelo digital do terreno do planalto da Humpata, com os principais lineamentos identificados no bordo do planalto.

- Sistema $\mathrm{N} 60^{\circ} \mathrm{E}$ a ENE-WSW - é o segundo sistema mais predominante deste setor. Identifica-se, sobretudo, nas regiōes centro e nordeste do bordo, formando corredores que se prolongam para a peneplanície adjacente e controlam a orientação e a forma sigmoidal do relevo. Traduz-se por falhas profundas do soco, fraturas e fendas. Podem reconhecer-se, quer nos taludes da Estrada da Leba, por vezes associados a deformação dúctil (Fig. 7), quer na estrada de acesso à Tundavala. Em alguns casos, as rochas aparecem profundamente cataclasadas, favorecendo a implantação de corpos doleríticos. Também se reconhecem em alguns 
afloramentos do planalto da Humpata. As falhas deste sistema terão atuado como zonas de transferência durante a fase de rifte do Cretácico inferior (HUDEC \& JACKSON, 2004).

- Sistema N-S a NNW-SSE - identifica-se, sobretudo, em afloramentos graníticos e quartzíticos no topo do planalto da Humpata (Fig. 6) e na extremidade nordeste deste setor. Parece favorecer a implantação de filóes doleríticos.

Menos significativos são os sistemas NNE-SSW e E-W que se identificam um pouco por todo o bordo.

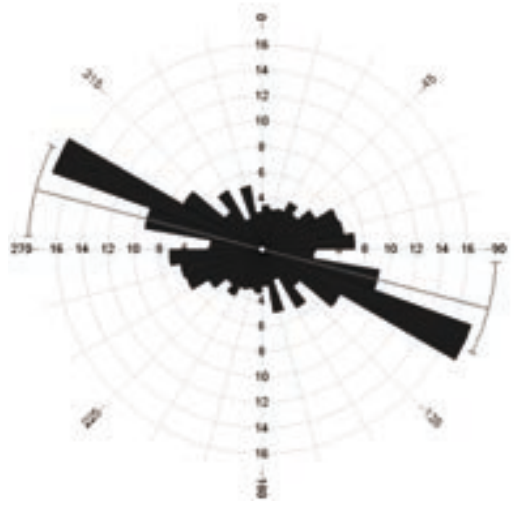

Fig. 4 - Diagrama de rosetas indicando a orientação dos lineamentos predominantes no bordo do planalto da Humpata.

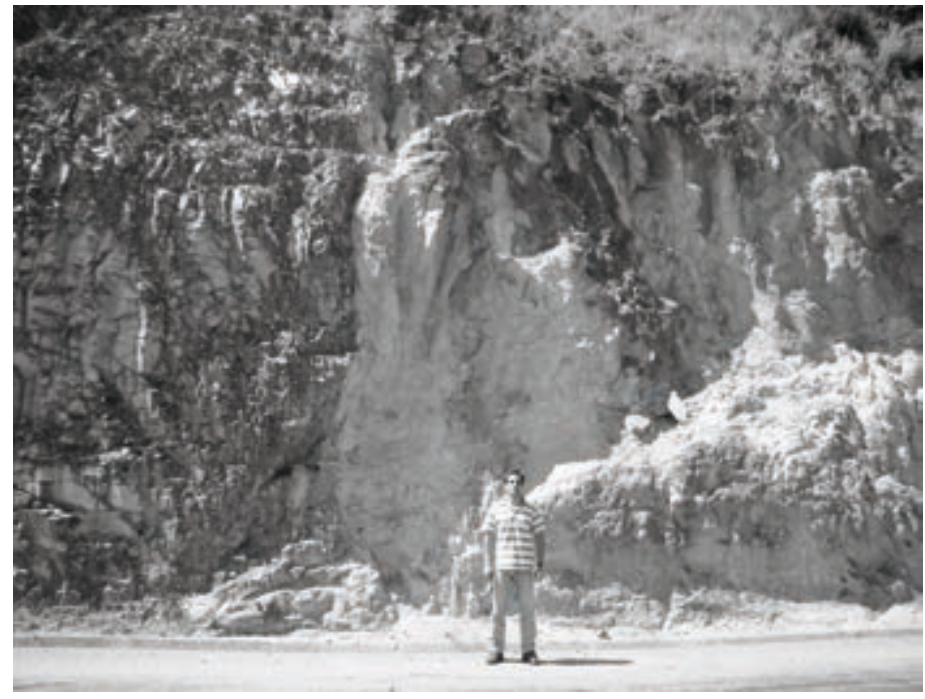

Fig. 5 - Estrada da Leba. Zona de cisalhamento frágil em granito. 


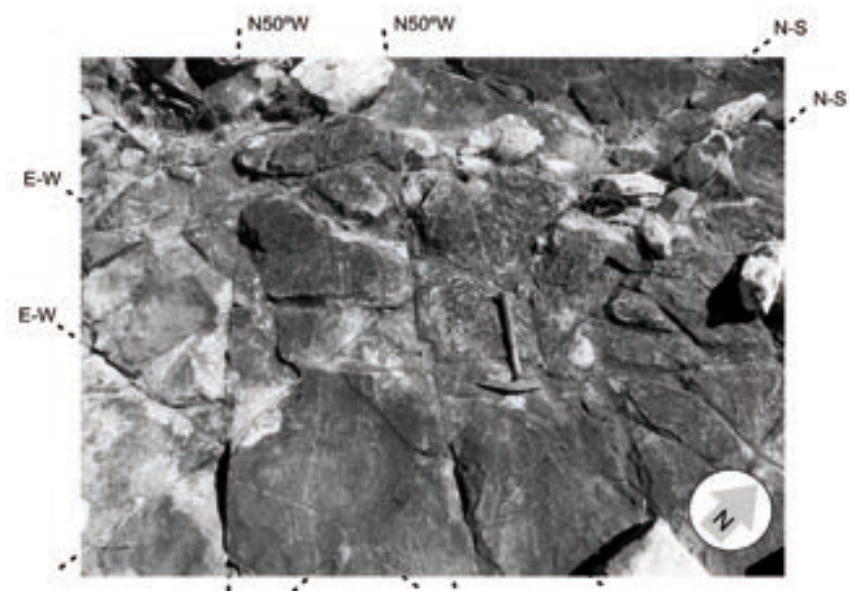

Fig. 6 - Sistemas de diáclases em afloramento quartzitico do planalto da Humpata.

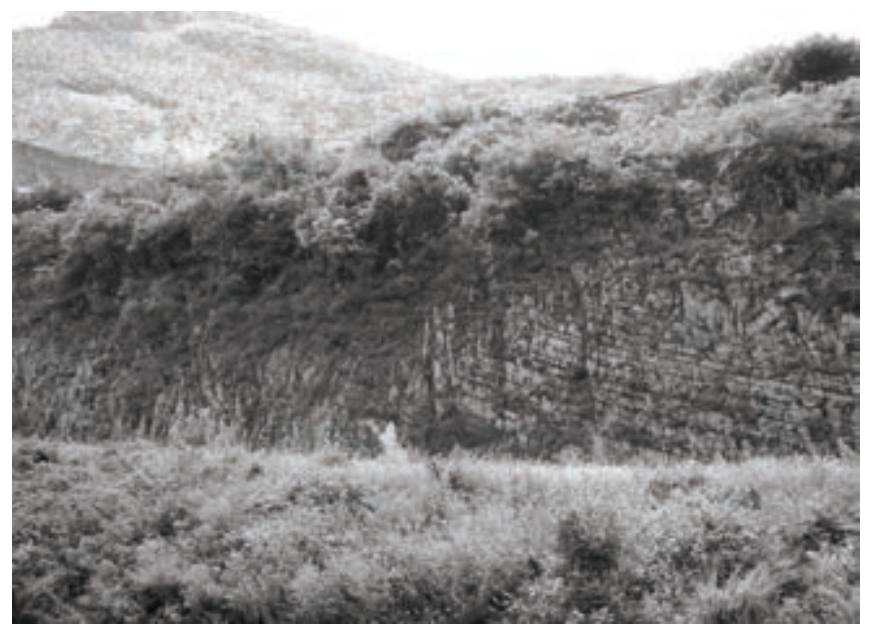

Fig. 7 - Talude da estrada da Leba - deformação frágil-dúctil em quartzitos.

\section{5 - Consideraçóes finais}

O presente estudo permitiu pôr em evidência aspetos da morfologia do bordo ocidental do planalto da Humpata e a identificação e caracterização dos diversos sistemas de lineamentos estruturais que nele se cruzam e que se materializam em falhas, fendas e fraturas. Os resultados obtidos têm importantes implicaçóes quer do ponto de vista da cartografia 
geológica e das interpretações tectónicas regionais, quer no âmbito das políticas de ordenamento do território. Dos contributos que advém deste estudo são de destacar: i) contributo no âmbito da cartografia regional e das interpretaçóes tectonoestruturais: este estudo permite aferir e complementar em detalhe a cartografia geológica regional, nomeadamente no que respeita ao padrão de fraturação do bordo ocidental do planalto da Huíla. Os grandes sistemas de lineamentos estruturais (N50W-N60W, N-S, N60E) tornam-se mais evidentes e são, de igual modo, destacadas orientaçóes (N10W-20W; $\mathrm{N} 20^{\circ} \mathrm{E}$; E-W) secundárias, o que constitui uma mais-valia para as interpretaçôes tectonoestruturais regionais. Reconhece-se a grande importância dos alinhamentos $\mathrm{N} 60^{\circ} \mathrm{E}$ e $\mathrm{N} 50^{\circ} \mathrm{W}-\mathrm{N} 60^{\circ} \mathrm{W}$ que, tal como nos outros setores do planalto da Huíla (MPENGO et al., 2011), e ao longo da margem, a oeste (HUDEC \& JACKSON, 2004), terão atuado, respetivamente, como falhas de transferência e falhas normais durante a fase de rifte do Cretácico inferior e terão sido responsáveis pelo traçado, recortado em facetas poligonais, do bordo ocidental do planalto da Húla; ii) contributo no âmbito da hidrogeologia: na medida em que o padrão de fraturas influencia a rede de drenagem (dendrítica a retangular) e a localização dos locais de recarga dos aquíferos existentes no planalto da Humpata. A informação obtida com este estudo será importante para o estabelecimento dos perímetros de proteção das zonas de recarga; iii) contributo no âmbito da estabilidade de taludes: as redes viárias que ligam o planalto às zonas baixas atravessam o bordo do planalto. A estabilidade dos seus taludes depende, para além do declive destes, do grau de fraturação e alteração das suas rochas constituintes, aliados às condiçóes climáticas. São frequentes os movimentos de massas, sobretudo a queda de blocos, com consequente interrupção das comunicaçóes viárias. De igual modo, ao longo de algumas encostas, sobranceiros às escarpas, onde o coberto vegetal é escasso, é comum encontrarem-se pequenos povoados, que vivem sob a ameaça dos movimentos de massa. $\mathrm{O}$ reconhecimento do padrão de fraturação poderá contribuir para a minimização dos riscos associados a estes processos.

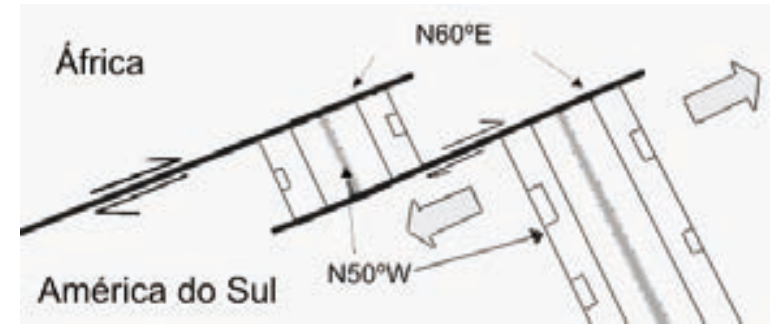

Fig. 8 - Modelo para o funcionamento dos sistemas N60E e N50\%W durante a fase de rifte do Cretácico inferior (adaptado de MPENGO et al., 2011).

Para trabalhos a realizar futuramente, sugere-se o prolongamento deste estudo, quer à zona interior do planalto da Huíla, quer à peneplanície adjacente a ocidente deste, o que permitirá adquirir uma maior perceçáo da dimensão e da continuidade lateral destes sistemas de lineamentos e da sua real importância na morfoestrutura e na evoluçáo geodinâmica desta região. 


\section{Referências Bibliográficas}

CHAVEZ, P. S., JR. (1996) - Image-based atmospheric corrections - Revisited and Improved. Photogrammetric Engineering and Remote Sensing 62, P. 1025-1036.

DElOR, C., TheVEniaUt, H., CAGE, M., PATO, D., LAFON, J.-M., BIALKOWSKI, A., ROOIG, J.-Y., NETO, A., CAVONGO, M. \& SERGEEV, S. (2008) - New insights into the Precambrian geology of Angola: basis for an updated lithochronological framework at 1:2000000 scale. 22nd Colloquium of African geology. Hammamet - Tunisia, p. 52-53.

CARVAlHO, H. (1983) - Notice explicative préliminaire sur la géologie d'Angola. Instituto de Investigação Tropical, Sér. Géol. Lisboa, 6, p. 15-30.

CARVAlHO, H. (1993) - The Precambrian of SW Angola and NW Namíbia. Com. Inst. Inv. Cient. Tropical, Lisboa, 4, 38 p.

FERREIRA DA SILVA, A. (2009) - A geologia da República de Angola desde o Paleoarcaico ao Paleozóico Inferior. Boletim de Minas, 44, p. 99-162.

HUDEC, M. R. \& JACKSON, M.P.A. (2004) - Regional restoration across the Kuanza Basin, Angola: salt tectonics triggered by repeated uplift of metastable passive margin. AAPG Bulletin, 88, p. 971-990.

MARQUES, M. M. (1977) - Esboço das unidades geomorfológicas de Angola (2a aproximação). Inst. Inv. Cient. Tropical, Garcia de Orta, Sérv. Geol., Lisboa, 2, p. 41-43.

MATIAS, D. N. (1980) - Carta Geológica de Angola à escala 1:1000000 (folha 3). Instituto Geográfico Cadastral.

MPENGO, H., LOPES, F. C., PEREIRA, A. \& MANTAS, V. (2011) - A detecção remota como suporte à caracterização morfo-estrutural do bordo ocidental do planalto da Huíla (SW de Angola). In: Neves, L. J. P. F., Pereira, A. J. S. C., Gomes, C. R. G., Pereira, L. C. G. \& Tavares, A. O. (eds.). Modelação de Sistemas Geológicos: Homenagem a M. M. Godinho. Laboratório de Radioactividade Natural da Universidade de Coimbra, p. 253-265. 